\title{
GEOSUL
}

\section{PADRÃO E DETERMINANTES DA INFRAESTRUTURA URBANA DAS MICRORREGIÕES BRASILEIRAS}

\author{
Gabriel Alves de Sampaio Morais ${ }^{1}$ \\ Diogo Brito Sobreira ${ }^{2}$ \\ João Eustáquio de Lima $^{3}$
}

\begin{abstract}
Resumo: Uma melhor infraestrutura urbana está associada com melhores índices de desenvolvimento. Nessa perspectiva, esta pesquisa procura encontrar os fatores do desenvolvimento urbano das microrregiões brasileiras. Para isso, utilizou-se a análise fatorial para encontrar padrões de desenvolvimento relacionados à infraestrutura urbana. Em seguida foi construído um índice permitindo ordenar as 558 microrregiões brasileiras e classificá-las em alto, médio e baixo grau de infraestrutura urbana. Foi possível extrair cinco fatores que explicam $72,58 \%$ da variância total dos dados. A maioria das microrregiões foi classificada com baixo grau de infraestrutura urbana, enquanto $14,69 \%$ das microrregiões foram classificadas com alto grau de infraestrutura, estando a maior parte na região Sudeste. Os estados de São Paulo e Minas Gerais lideraram o ranking com o maior número de microrregiões com alto grau de infraestrutura urbana. O contrário ocorreu para a região Norte, a qual não obteve microrregiões com alto grau de infraestrutura.
\end{abstract}

Palavras-chave: : Infraestrutura Urbana; Desenvolvimento Regional; Análise Fatorial

\section{PATTERN AND DETERMINANTS OF THE BRAZILIAN MICROREGIONS URBAN INFRASTRUCTURE}

\begin{abstract}
A better urban infrastructure is associated with better development indexes. In this perspective, this research tried to find the factors of urban development of the Brazilian micro-regions. For this, we used factor analysis to find patterns of development related to urban infrastructure. Then it built an index allowing to order the 558 Brazilian micro-regions and classify them into high, medium and low level of urban infrastructure. It was possible to extract five factors that explain $72,58 \%$ of the total variance of the data. Most micro-regions were classified as low level of urban infrastructure, while 14,69\% of micro-regions were classified with high infrastructure, with most in the Southeast. The states of São Paulo and Minas Gerais led the ranking with the highest number of micro-regions with high urban infrastructure. The opposite was observed to the North, which got no micro-regions with high infrastructure.
\end{abstract}

Keywords: Urban Infrastructure; Regional Development; Factor Analysis

\footnotetext{
${ }^{1}$ Doutorando do Programa de Pós-graduação em Economia Aplicada (PPGEA), Universidade Federal de Viçosa (UFV). E-mail: gabriel.sampaio@ufv.br

${ }^{2}$ Doutorando do Programa de Pós-graduação em Economia Aplicada (PPGEA), Universidade Federal de Viçosa (UFV). E-mail: economistdbs@ @otmail.com

${ }^{3}$ Ph.D. em Economia Rural, Michigan State University. Professor Titular do Departamento de Economia Rural (DER), Universidade Federal de Viçosa (UFV). jelima@ufv.br
} 


\section{PATRÓN Y DETERMINANTES DE LA INFRAESTRUCTURA URBANA DE LAS MICRORREGIONES BRASILEÑAS}

Resumen: Una mejor infraestructura urbana está relacionada con mejores índices de desarrollo. Con esta perspectiva, el objetivo de este articulo ha sido encontrar los factores de desarrollo urbano de las microrregiones brasileñas. Se utilizó el análisis factorial para encontrar patrones de desarrollo relacionados con la infraestructura urbana. A continuación se construyó un índice, lo que ha permitido ordenar las 558 microrregiones brasileñas y clasificarlas en alto, médio y bajo grado de infraestructura urbana. Ha sido posible extraer cinco factores que explican $72,58 \%$ de la variación total de los datos. La mayoria de las microrregiones se clasificaron con bajo grado de infraestructura urbana, mientras que el $14,69 \%$ de las microrregiones se clasificaron con alto grado de infraestructura, encontrándose la mayor parte en la región Sudeste. Los estados de São Paulo y Minas Gerais lideraron el ranking con el mayor número de microrregiones con alto grado de infraestructura urbana. Lo opuesto ocurrió en la región Norte, en la cual no se identificaron microrregiones con alto grado de infraestructura.

Palabras-Clave: Infraestructura Urbana; Desarrollo Regional; Análisis Factorial

\section{INTRODUÇÃO}

Um estudo sobre os padrões de desenvolvimento econômico ao nível de microrregiões pressupõe o entendimento teórico e conceitual do desenvolvimento econômico e das relações entre os fatores importantes na determinação destes padrões. O desenvolvimento é um conceito muito abrangente que leva em conta aspectos econômicos, políticos, sociais e culturais, embora questões de cunho econômico e social sejam geralmente mais importantes, tais como, renda, emprego, saúde, educação, alimentação, segurança, transporte, lazer e moradia.

Segundo Clemente e Higachi (2000), uma referência à região passa pelo conceito de espaços econômicos de Perroux e parte do princípio de que certas áreas econômicas têm origem da atividade humana, em que as relações sociais e produtivas vigentes se guiam no sentido do desenvolvimento das forças produtivas e, portanto, na busca do bem estar social. Para a análise do padrão de desenvolvimento das microrregiões, é preciso compreender a forma geoespacial de organização dos estados e os impactos de políticas públicas, nomeadamente de cunho regional com objetivo de elevar o grau de integração do processo de desenvolvimento econômico.

O tema desenvolvimento já é bastante discutido na literatura econômica. Contudo, esse conceito vem mudando e deixando de abranger somente aspectos econômicos. Nessa 
perspectiva, além do crescimento da renda per capita, fatores relacionados à educação, saúde e infraestrutura urbana têm, cada vez mais, pautado as discussões em busca de resultados que coloquem as regiões em patamares mais elevados de bem estar social. Cabe ressaltar também as discussões do desenvolvimento regional que abordam os fatores e as consequências da grande heterogeneidade dos estágios de desenvolvimento entre as regiões (HADDAD et. al, 1989). Com isso, o tema das desigualdades regionais se constitui em um dos aspectos mais relevantes do processo de desenvolvimento. Essas discussões iniciaram-se na década de 1950 principalmente com Perroux, Myrdal e Hirschman.

Em complementaridade aos aspectos de cunho econômico e social para o desenvolvimento de uma região considerada um centro urbano, a infraestrutura das cidades está intimamente ligada a este desenvolvimento, isto é, entende-se que uma região que tem infraestrutura urbana bem desenvolvida oferece à população melhores condições de saúde, de saneamento básico, de mobilidade urbana, de educação e de acesso aos meios de comunicação e eletrificação, além de melhores condições físicas do entorno dos domicílios que neles residem.

Nessa perspectiva, propõe-se elaborar um índice da infraestrutura urbana que represente o desenvolvimento em termos da infraestrutura física desse meio, pretendendo-se preencher uma lacuna na literatura que trata de medidas que buscam mensurar o desenvolvimento das microrregiões em relação à dimensão “infraestrutura urbana”, uma vez que esta possui relação direta com o desenvolvimento.

A análise é baseada em variáveis e critérios já consolidados em indicadores de bem estar urbano, bem como pela incorporação de novas variáveis que melhor represente o desenvolvimento regional em termos dessa infraestrutura, como características do sistema educacional; mercado de trabalho; entorno dos domicílios; saneamento urbano; eletrificação; acessibilidade às pessoas com deficiência; e sistema de saúde.

Sabe-se que as decisões tomadas sobre política macroeconômica, ao nível nacional, evidentemente, condicionam as possibilidades reais para promover atividades negociadas e coerentes de desenvolvimento ao nível meso e microrregional (TURRA; BAÇO, 2014).

De acordo com Sepúlveda (2005), a microrregião se concebe como aquele espaço mínimo no qual é possível executar atividades de natureza diversa, como a proteção de recursos naturais estratégicos e o desenvolvimento de programas orientados a potencializar as 
capacidades produtivas da comunidade e de combate à pobreza, além de garantir o desenvolvimento da infraestrutura urbana.

Assim, a microrregião se define como aquela unidade territorial na qual se desenvolvem os processos típicos do desenvolvimento em quaisquer de suas dimensões (TAVARES, 2010). Nesse contexto, os critérios de definição física de uma microrregião e a utilização dessas como unidades de planejamento são flexíveis e fáceis para adaptar-se a cada circunstância.

Nesse sentido, a análise em nível de microrregiões pretende precisamente integrar a dimensão político-administrativa com a dimensão que se relaciona com a organização econômica e social, responsável por constituir um cenário apropriado à execução de atividades de planejamento (UDERNAN, 2008).

Em suma, o que se pretende é orientar a ação para uma unidade territorial na qual se possam realizar diagnósticos que sirvam de base a estratégias de desenvolvimento e que conduzam a programas de investimentos e projetos específicos de infraestrutura urbana, como parte de um processo de planejamento descentralizado, orientado por uma instância de governo local ou regional com uma perspectiva multidimensional de longo prazo.

Não obstante, a análise em nível microrregional está alinhada com o modelo gerencial de administração pública adotada no Brasil nos anos 90, onde um de seus enfoques é a descentralização dos processos, o que deu mais autonomia aos governos regionais na formulação e execução de políticas públicas que mais se adéquam as necessidades da região em questão de modo a obter a máxima eficiência dos serviços públicos (FERREIRA, 2013).

Portanto, o índice aqui proposto serve de fundamento ao planejamento na tomada de decisões que promovam equidade na distribuição e no acesso da população a bens de cidadania, especialmente no que se refere á distribuição de recursos de infraestrutura, entendida como uma das formas de atenuar as disparidades sócio-espaciais das cidades, além de servir como suporte teórico na construção de dimensões de índices agregados que envolva a promoção da qualidade de vida urbana, do desenvolvimento urbano, bem como da elevação do bem-estar social nas microrregiões brasileiras.

O artigo está divido em quatro seções além desta introdução. Na seção seguinte será feita uma revisão da literatura na tentativa de conceituar o que venha a ser a infraestrutura urbana, bem como uma explanação acerca da evolução dos indicadores urbanos no Brasil. Na terceira seção será apresentada a estratégia empírica para a elaboração do índice de 
infraestrutura urbana das microrregiões. Na quarta seção serão apresentados os resultados e discussões, e por fim, na última seção, as principais conclusões da pesquisa.

\section{REVISÃO DE LITERATURA}

A expansão demográfica observada desde o último século fez também aumentar o tamanho das cidades e consequentemente da população residente em aglomerações urbanas. Entretanto, o ingresso em uma sociedade urbana vai além de sua expressão demográfica e alcança preocupações em como a cidade está estruturada em servir a demanda da população em relação aos serviços e aparelhos urbanos, ou seja, a infraestrutura urbana.

A partir dos anos 60 a estruturação das cidades ganha escopo entre pesquisadores e instituições de todo o mundo no sentido de como o crescimento acelerado da urbanização pode influenciar a vida das pessoas e como podem emergir soluções de infraestrutura urbana que atendam as necessidades básicas da população, tais como saneamento básico, características do entorno dos domicílios, eletricidade, coleta de lixo, etc. (NAHAS, 2003).

Segundo o IPEA (2010), o crescimento urbano do Brasil não foi de exclusividade de uma ou duas grandes metrópoles. Ao contrário, caracterizou-se pela emergência de diversas metrópoles e cidades médias no vasto território brasileiro, por meio de um processo de urbanização complexo e diversificado, que, apesar de suas especificidades, reproduz a tendência mundial de migração campo-cidade e de avanço da urbanização.

Nesse sentido, houve uma mobilização entre pesquisadores e instituições na definição do que seria uma infraestrutura urbana de qualidade, ou aquela que atendesse a população de modo a não gerar desigualdades sócio-espaciais. Zmitrowicz e Neto (1997) definem como infraestrutura urbana o conjunto de sistemas técnicos de equipamentos e serviços necessários ao desenvolvimento das funções urbanas, podendo estas serem vistas sob os aspectos sociais (condições adequadas de moradia, trabalho, saúde, educação, lazer e segurança); sob aspectos econômicos (a infraestrutura urbana deve propiciar a produção e comercialização de bens e serviços); e sob o aspecto institucional (meios necessários ao desenvolvimento das atividades político-administrativas, incluindo a gerência da própria cidade). Assim, para os autores, a infraestrutura urbana tem como objetivo final a prestação de um serviço, pois, por ser um sistema técnico, requer algum tipo de operação com o usuário. 
Encontra-se também na literatura distinções conceituais acerca do tema da infraestrutura urbana entre infraestrutura leve (soft infrastructure) e infraestrutura pesada (hard infrastructure). A definição de infraestrutura leve conceituada por Blakey e Bradshaw (2002) e Stimson et. al (2006) estaria relacionada às instituições e outros inputs necessários para manter a dinâmica econômica, social e cultural de uma localidade, tais como educação, pesquisa, saúde, know-how produtivo, governança, assessoria aos negócios e ao meio ambiente, dentre outros fatores, incluindo amenidades que garantem uma certa qualidade de vida. Outro termo semelhante é o adotado por Smilor e Wakelin (1990), que definem como infraestrutura inteligente (smart infrastructure) ao se referirem a infraestrutura leve, como sendo aquela que contém elementos que tem se transformado em determinantes da competitividade de cidades e regiões.

Já a infraestrutura pesada estaria relacionada aos equipamentos e aparelhos físicos urbanos necessários para um bom funcionamento das cidades modernas, isto é, as rodovias, o subsistema de saneamento básico (as redes de água e esgoto e coleta de lixo), os terminais de movimentação de cargas e passageiros (aeroportos, portos, rodoviárias), os sistemas de telecomunicações, as características do entorno dos domicílios, escolas, hospitais, dentre outros (IPEA, 2010). De acordo com Abiko (1995) e ressaltado por Choguill (1996), quando se considera o conceito de infraestrutura urbana pesada, esta deve contar primordialmente com serviços de abastecimento de água seguro e em quantidade suficiente, serviços de eliminação de dejetos domésticos e humanos e drenagem e gestão de resíduos sólidos, a fim de alcançar a sustentabilidade nas cidades e o atendimento das necessidades humanas básicas.

Em um estudo publicado pelo Banco Interamericano de Desenvolvimento - BID (2000) a infraestrutura urbana pode ser classificada em: (i) econômica (transporte, energia e telecomunicações); (ii) social (sistema de água potável e esgotamento sanitário, educação, saúde, dentre outros); (iii) ambiental; e (iv) acesso ao conhecimento. Esta definição é consoante à apresentada pela OCDE (1991), que qualifica a infraestrutura urbana como um amplo conjunto de suportes essenciais no dia a dia das cidades modernas.

Na prática, dada a abrangência na definição do que seja a infraestrutura urbana, autores como Estache e Fay (2007) e Gianpiero (2009) concordam que existem tantas definições de infraestrutura quantas forem as demandas das necessidades básicas da população a serem atendidas. Essa infraestrutura, como salienta Audretsch e Feldman (1996), corresponde a um bem de capital ou serviço público que colabora para o desenvolvimento 
econômico e para o aumento do bem-estar social através das externalidades positivas geradas por essa infraestrutura.

Assim, a disponibilidade de infraestrutura constitui para a cidade um indicador das suas condições de desenvolvimento, enquanto que sua ausência limita o processo de desenvolvimento econômico e territorial (IPEA, 2010). Entende-se, portanto, que a quantidade e a qualidade da infraestrutura disponível no território qualificam e condicionam seu processo de desenvolvimento.

\section{Evolução dos Indicadores Urbanos no Brasil}

As primeiras tentativas de elaboração de indicadores da qualidade de vida e que orientassem o planejamento público teve seu marco na década de 60 , onde até então abordavam exclusivamente aspectos econômicos do desenvolvimento, não levando em conta outros aspectos da vida urbana.

Entretanto, na década de 70 a discussão sobre qualidade de vida ganha um novo enfoque devido aos problemas sociais e ambientais decorrente da crescente urbanização, onde procurou-se levar em conta as consequências da vida no ambiente urbano, como por exemplo, as desigualdades sociais e a degradação ambiental que ameaçam a sustentabilidade do desenvolvimento humano (NAHAS et. al, 2006).

As discussões sobre indicadores sociais e ambientais teve sua convergência na década de 90, especialmente com a realização da Conferência Mundial sobre o Meio Ambiente e Desenvolvimento (ECO-92) e da implantação do "Programa de Indicadores Urbanísticos para Monitoramento de Assentamentos Urbanos", do Habitat $\mathrm{II}^{4}$, que reafirma e propõe o uso de indicadores e de índices para o monitoramento das condições de vida no meio urbano (NAHAS, 2003).

Ainda sobre o monitoramento do ambiente construído, Fiori et. al (2008) defende que os indicadores de infraestrutura urbana representam um avanço significativo para a utilização de um instrumento de monitoramento do espaço urbano, viabilizando a mensuração e o acompanhamento das evoluções do ambiente construído, facilitando a compreensão do

\footnotetext{
${ }^{4}$ O Habitat II (Istambul, 1996) foi um evento realizado pelo "Programa das Nações Unidas para os Assentamentos Humanos (UN-HABITAT)" que tem seu enfoque sobre a questão urbana e que colabora com países prestando assessoria técnica para enfrentar o número crescente de desafios de infraestrutura urbana enfrentados por cidades de todos os tamanhos.
} 
espaço, possibilitando o estabelecimento de diretrizes, além de permitir elencar prioridades de ações, de maneira a minimizar a degradação do ambiente urbano.

No Brasil, uma das primeiras investidas na tentativa de mensurar a qualidade de vida urbana que levou em consideração aspectos de infraestrutura urbana foi realizada na cidade de Curitiba, que desde 1987 desenvolve o Índice Sintético de Satisfação da Qualidade de Vida (ISSQV) formulado pelo Instituto de Pesquisa e Planejamento Urbano de Curitiba (IPPUC). O ISSQV é composto por indicadores georreferenciados de bairros e tem como objetivo expressar o acesso da população a habitação, saúde, educação e transporte (IPPUC, 1996).

Seguindo nessa mesma linha, mas agora para as 181 cidades mais populosas do Brasil e utilizando dados do Censo Demográfico de 1991, o Instituto Pólis publicou o estudo "Evolução Comparada da Qualidade de Vida nos Municípios Brasileiros - O Melhor Desempenho de uma Prefeitura", onde foi apresentado o Índice Municipal do Instituto Pólis, que abrangeu dimensões como renda, habitação, alfabetização e meio ambiente. Esta última dimensão envolveu aspectos relacionados à infraestrutura urbana, tais como abastecimento de água, rede de esgoto e coleta de lixo (INSTITUTO PÓLIS, 1994).

No anseio do entendimento dos determinantes da qualidade de vida urbana, a prefeitura de Belo Horizonte (1994) juntamente com instituições de pesquisa se propuseram a mensurar a qualidade de vida urbana elaborando um índice dimensional intraurbano, que quantificou a desigualdade espacial no interior do tecido urbano em termos de disponibilidade e acesso a bens e serviços urbanos. O objetivo foi avaliar o nível da infraestrutura de serviços urbanos disponíveis nas regiões da cidade, o que permitiu a delimitação de áreas prioritárias para os investimentos públicos. O indicador ficou conhecido como Índice de Qualidade de Vida Urbana de Belo Horizonte (IQVU-BH) e foi composto por 38 indicadores agrupados em 10 variáveis, tendo a infraestrutura urbana como uma de suas dimensões (FJP \& IPEA, 1998)

$\mathrm{Na}$ sequência, na tentativa de adequar as propostas do Habitat II, alguns indicadores urbanos no Brasil foram realizados na década de 90 nas cidades de Curitiba, Rio de Janeiro, Brasília e Recife (BRASIL, 1996), além dos municípios mineiros através do Índice de Condições de Vida (ICV) realizado pela Fundação João Pinheiro (FJP) e o Instituto de Pesquisa Econômica Aplicada (IPEA). Em 1998, essas duas instituições juntamente com o Programa das Nações Unidas para o Desenvolvimento (PNUD Brasil) foram convidadas a ampliarem o ICV para todos os municípios brasileiros, além de elaborarem o Índice de 
Desenvolvimento Humano Municipal (IDHM) baseado no tradicional Índice de Desenvolvimento Humano - IDH (PNUD, 2013).

O ICV é uma extensão do IDH e procura com base em metodologia similar, aumentar o número de dimensões e de indicadores básicos referentes às condições de vida que já estavam presentes no IDHM. Os 20 indicadores utilizados na construção do ICV foram agregados em 5 grupos: Renda, Educação, Infância, Habitação e Longevidade. Na dimensão Habitação levou-se em consideração a densidade e a durabilidade domiciliar, bem como o abastecimento adequado de água e instalação adequada de esgoto (PNUD; IPEA \& FJP, 2010).

Seguindo com a proposta de construção de novos indicadores e utilizando dados do Censo Demográfico do Instituto Brasileiro de Geografia e Estatística (IBGE) para o ano 2000, o IPEA se encarregou de construir um indicador que medisse o grau de vulnerabilidade social das cidades brasileiras, dando origem ao Indicador de Vulnerabilidade Social dos Municípios $(\mathrm{IVS})^{5}$, composto por três dimensões, a saber, Renda e Trabalho, Capital Humano e Infraestrutura Urbana. Esta última dimensão propõe acompanhar parcelas da população que vivem em domicílios com água e esgotamento sanitário inadequado, e ausência de coleta de lixo, bem como a parcela da população de baixa renda que gasta mais de uma hora de casa para o trabalho, incluindo a questão da mobilidade urbana.

Com a disponibilização do Censo Demográfico (IGBE) para o ano de 2010, o IVS foi atualizado pelo IPEA dando origem a publicação do Atlas da Vulnerabilidade Social dos Municípios Brasileiros, permitindo fazer um acompanhamento temporal do IVS (IPEA, 2015).

Devido ao sucesso e repercussão do Índice de Qualidade de Vida Urbana de Belo Horizonte (IQVU-BH), o Instituto de Desenvolvimento Humano Sustentável (IDHS) da Pontifícia Universidade Católica de Minas Gerais (PUC Minas) com respaldo e apoio do Ministério das Cidades, desenvolveu então o Índice de Qualidade de Vida Urbana-Brasil (IQVU-BR). Tomando como referência teórico-metodológica a experiência do índice desenvolvido inicialmente para a capital mineira, o IQVU-BR avalia a qualidade de vida urbana dos municípios brasileiros, e tem foco na oferta dos serviços urbanos existentes nesses

\footnotetext{
${ }^{5}$ O IVS já havia sido calculado para o município de Belo Horizonte em 1999, sendo o elemento central do Mapa da Exclusão Social da cidade, abrangendo 5 dimensões: "Ambiental" (Acesso à habitação e a infraestrutura básica); "Cultural" (Acesso a escolaridade); "Econômica" (Acesso a renda e ao trabalho); "Jurídica" (Acesso a assistência jurídica) e "Segurança e Sobrevivência" (Acesso à saúde, segurança alimentar e previdência social) (NAHAS et. al, 2000).
} 
municípios e a possibilidade espacial de acesso a esses serviços e a qualidade ambiental (NAHAS, 2006).

Pode-se elencar outros indicadores em nível nacional que sintetizam diferentes aspectos urbanos como um fator determinante ao desenvolvimento, como o Índice de Exclusão Social (IES), o Índice de Carência Habitacional (ICH), o Índice de Qualidade Institucional dos Municípios (IQIM), o Índice do Potencial de Desenvolvimento do Município (IPDM) e o Índice Municipal (IM).

Na confluência do entedimento de que o produto final decorrente dos serviços urbanos é a elevação do bem-estar social, o Instituto Nacional de Ciência e Tecnologia (INCT) através do Observatório das Metrópolis divulgou em 2010 o Índice de Bem Estar Urbano (IBEU) e relaciona as condições coletivas de vida promovidas pelo ambiente construído da cidade, nas escalas de habitação e de sua vizinhança próxima, e pelos equipamentos e serviços urbanos. Por exercerem funções de direção, comando e coordenação dos fluxos econômicos, o IBEU foi calculado apenas para as 15 regiões metropolitanas do Brasil (INCT, 2013).

Construído a partir do Censo Demográfico do IBGE (2010) e possuindo 5 dimensões mobilidade urbana; condições ambientais urbanas; condições habitacionais urbanas; atendimento de serviços coletivos urbanos; e infraestrutura urbana - o IBEU é o indicador que mais se aproxima do indicador proposto por essa pesquisa. A diferença básica é que o IBEU procura dar uma medida ao bem estar da população que vive em regiões metropolitanas, enquanto que o indicador aqui proposto tem seu foco primordial nos serviços e aparelhos de infraestrutura urbana para as 558 microrregiões brasileiras, entendendo que esta infraestrutura seja, dentre outros fatores, um dos determinantes da elevação do bem estar social.

Em outras palavras, enquanto que o IBEU na sua dimensão "Condições Habitacionais Urbanas" se preocupa, por exemplo, com a densidade populacional por dormitório e por banheiro, bem como o tipo de parede dos domicílios e seu tipo, entende-se aqui que essas características domiciliares são de escolhas individuais dos agentes. Portanto, ao se tratar da urbanização, mais especificamente da infraestrutura urbana, esse estudo se afasta da concepção de bem-estar decorrente do consumo individual e mercantil, passando a pensar no coletivo. Consequentemente, quando se leva em conta o coletivo, a responsabilidade por esses serviços urbanos é papel do Estado ou da parceria público-privada.

Portanto, a concepção de infraestrutura proposta nesta pesquisa decorre da compreensão daquilo que uma região deve propiciar às pessoas em termos de condições 
materiais de vida, tendo o desenvolvimento, a qualidade de vida e a elevação do bem-estar social e urbano como uma consequência da oferta desses serviços.

\section{ESTRATÉGIA EMPÍRICA}

A estratégia empírica para elaborar um indicador que melhor represente a infraestrutura urbana das microrregiões brasileiras se deu por meio da análise fatorial, que tem como princípio básico a redução do número original de variáveis por meio da extração de fatores independentes, de tal forma que estes fatores possam explicar, de forma simples e reduzida, as variáveis originais.

Hoffman (1992) indica que a análise fatorial pelo método dos componentes principais é um instrumental indicado pelos pesquisadores, pois possibilita inferir um número pequeno de fatores que passarão a ser utilizados como indicadores que mais influenciam no desenvolvimento das microrregiões.

Em suma, esta técnica permite extrair um número reduzido de fatores, que são combinações lineares das variáveis originais, perdendo o mínimo de informações. Este método de análise é muito empregado, como aponta Haddad et al. (1989), para juntar regiões ou locais de acordo com a similaridade de seus perfis; e agrupar variáveis para delinear padrões de variações nas características.

Cada um dos fatores consiste em uma combinação linear das variáveis originais padronizadas incluídas no estudo. Alguns princípios dão suporte na composição destes fatores: as variáveis mais correlacionadas combinam-se dentro de um mesmo fator; as variáveis que compõem um fator são praticamente independentes das que compõem outros fatores; a derivação dos fatores processa-se, visando maximizar a percentagem de variância total relativo a cada fator consecutivo; e os fatores não são correlacionados entre si. Procurase, assim, determinar os coeficientes que relacionam as variáveis observadas com os fatores comuns. Esses coeficientes denominados de cargas fatoriais desempenham a mesma função dos coeficientes de correlação (FERREIRA JÚNIOR, BAPTISTA E LIMA, 2004).

Segundo Lemos (2000), em geral a estrutura inicial das estimativas das cargas fatoriais não é definitiva. Para confirmar ou rejeitar esta estrutura, o método proporciona a possibilidade de se fazer sua rotação. A rotação de fatores auxilia ao pesquisador facilmente interpretar esses fatores. Existem vários métodos de rotação, e o mais conhecido deles é a 
rotação ortogonal pelo método Varimax, que procura minimizar o número de variáveis fortemente relacionadas com cada fator, permitindo, assim, obter fatores mais facilmente interpretáveis. De acordo com Mingoti (2007), o método Varimax produz soluções mais práticas que os outros métodos.

Assim, o modelo de análise fatorial pode ser expresso algebricamente da seguinte forma:

$$
X_{i}=a_{i 1} F_{1}+a_{i 2} F_{2}+\ldots+a_{i m} F_{m}+e_{i}
$$

em que $X_{i}$ representa o i-ésimo escore da variável padronizada, com média zero e variância unitária $(\mathrm{i}=1,2, \ldots \mathrm{m}) ; F_{j}$ indica os fatores comuns não correlacionados, com média zero e variância unitária; $a_{i j}$ representa as cargas fatoriais, e $e_{\bar{i}}$, o termo de erro que capta a variação especifica de $X_{i}$ não explicada pela combinação linear das cargas fatoriais com os fatores comuns e imprecisões de medição de variáveis em função de erro de observação, de mensuração, e de especificação do modelo.

Uma medida importante para na análise é o somatório das cargas fatoriais ao quadrado. Ela indica a variância comum ou comunalidade, isto é, o quanto da variância total de $X_{i}$ é explicada pela solução fatorial. As comunalidades das variáveis que não têm explicação suficiente no modelo são aquelas menores que 0,5. Por fim, o critério utilizado para definir o número de fatores foi o de considerar apenas aqueles que possuem raiz característica ou autovalor maior que um (JOHNSON; WICHERN, 1992).

Após o cálculo das cargas fatoriais e a identificação dos fatores comuns, torna-se necessário a estimação do escore fatorial, por meio do método semelhante ao de regressão. De acordo com Ferreira Júnior et al. (2004), o escore para cada observação (microrregião), é, portanto, resultado da multiplicação do valor (padronizado) das variáveis pelo coeficiente do escore fatorial correspondente, sendo a expressão geral para estimação do j-ésimo fator, $F_{j}$, dada por:

$$
F_{j}=W_{j 1} X_{1}+W_{j 2} X_{2}+W_{j 3} X_{3}+\ldots+W_{j p} X_{p}
$$

em que os $W_{j i}$ são os coeficientes dos escores fatoriais e $p$ é o número de variáveis.

Para testar a adequabilidade do modelo de análise fatorial, geralmente utiliza-se a estatística de Kaiser-Meyer-Olkin (KMO) e o Teste de Esfericidade de Bartlett. O KMO é um indicador que compara a magnitude do coeficiente de correlação observado com a magnitude do coeficiente de correlação parcial. Quando as correlações parciais são próximas de zero, o 
coeficiente de KMO está próximo de um, o que indica a adequabilidade de ajuste do modelo de análise fatorial. Um coeficiente abaixo de 0,5 exige medidas de correção nos dados amostrais através da exclusão ou inclusão de novas variáveis. (MINGOTI, 2007).

Por sua vez, o Teste de Esfericidade de Bartlett serve para testar a hipótese nula de que a matriz de correlação é uma matriz identidade. Isto é: $H_{0}: P_{p x p}=I_{p x p}$ contra $H_{1}: P_{p x p} \neq I_{p x p}$. Ainda de acordo com Mingoti (2007), se esta hipótese for rejeitada, os dados são adequados e a análise fatorial pode ser realizada.

A partir da matriz dos escores fatoriais, é possível construir um índice para hierarquizar as observações (microrregiões). Salienta-se que os escores fatoriais de cada fator possuem distribuição normal, com média zero e variância unitária e, desse modo, podem ser utilizadas para indicar a posição relativa de cada observação relativamente ao conceito expresso pelo fator.

A verificação do grau da infraestrutura urbana de cada microrregião brasileira foi feita por meio dos escores fatoriais, ou seja, dos valores dos fatores para cada uma das 558 observações (microrregiões) por meio da equação (3). Assim, na obtenção do Índice Bruto de Infraestrutura Urbana (IBIU) para que se possa fazer um rank das microrregiões, realizou-se o cálculo da média dos fatores, ponderadas pela variância, pertencentes a cada observação. A ponderação pela proporção de explicação da variância total (dada pelo valor da raiz característica) exprime a importância relativa de cada fator. De acordo com Melo (2007), o IBIU pode ser expresso da seguinte forma:

$$
I B I U=\frac{\sum_{i=1}^{n}\left(w_{i} F_{i}\right)}{\sum_{i=1}^{n}\left(w_{i}\right)}
$$

onde $w_{i}$ é a proporção da variância explicada por cada fator (raiz característica) e; $F_{i}$ são os escores fatoriais.

A partir do Índice Bruto de Infraestrutura Urbana (IBIU) pode-se obter o Índice de Infraestrutura Urbana (IIU) proposto para cada microrregião. O IIU foi construído a partir do método min-max, em que o maior valor adquire o valor cem e o menor zero, ou seja, a variação do índice ocorre no intervalo entre 0 e 1, sendo os valores intermediários obtidos por interpolação (PEROBELLI et al.,1999).

O Índice de Infraestrutura Urbana é dado por:

$$
I I U_{q c}=\frac{x_{q c}-\min _{c}\left(x_{q}\right)}{\max _{c}\left(x_{q}\right)-\min _{c}\left(x_{q}\right)}
$$


onde $x_{q c}$ é o valor da observação $(q)$ do índice bruto para a microrregião $(c)$; $\min _{c}$ é o menor valor do índice bruto dentre todas as microrregiões; e $\max _{c}$ é o maior valor do índice bruto dentre todas as microrregiões.

A obtenção do Índice de Infraestrutura Urbana (IIU) nos possibilita fazer uma ordenação das microrregiões brasileiras. Baseando-se na classificação feita em Xerxenevsky e Fochezatto (2015), foram considerados com grau de desenvolvimento alto (A), aquelas microrregiões que apresentaram resultados com um desvio-padrão acima da média; médio (M), aquelas com valores entre a média e um desvio-padrão acima da média; e por fim, baixo (B), as microrregiões com índice abaixo da média. A Tabela 1 sintetiza as categorias, conforme os desvios-padrão em torno da média.

Tabela 1 - Categorização da Infraestrutura Urbana das Microrregiões Brasileiras

\begin{tabular}{c|c|c}
\hline Grau de Desenvolvimento & Sigla & Desvios-padrão $(\delta)$ em torno da média \\
\hline \hline Alto & A & $I I U \geq(M+\delta)$ \\
\hline Médio & M & $M \leq I I U<(M+\delta)$ \\
\hline Baixo & B & $I I U<M$ \\
\hline
\end{tabular}

Legenda: IIU - Índice de Infraestrutura Urbana; $\delta$ - Desvio-padrão; M - Média

\section{Base de Dados}

Objetivando detectar os potenciais da infraestrutura urbana das microrregiões brasileiras foram utilizadas 20 variáveis, observadas em cada uma das 558 microrregiões do Brasil. A escolha das variáveis se deu com o intuito de reproduzir o estágio de desenvolvimento da infraestrutura urbana de cada microrregião. Na Tabela 2 estão sintetizadas as variáveis utilizadas no estudo e tem como base o ano de 2010. Todas as variáveis foram coletadas do Sistema IBGE de Recuperação de Dados Automática (SIDRA), exceto a variável quantidade de estabelecimentos de saúde, que foi coletada do Banco de Dados do Sistema Único de Saúde (DATASUS).

De acordo com Melo e Parré (2007), diversos são os estudos que incluem e concluem sobre a importância da educação no desenvolvimento de regiões. Espera-se que um maior número de matrículas escolares seja acompanhado de uma melhor infraestrutura da rede de ensino e consequentemente da infraestrutura urbana ao serviço de educação. Nessa perspectiva, o aspecto da educação é captado pelas variáveis X01 a X04. 
O indicador X05 procura relacionar o desenvolvimento urbano com a força de trabalho, mais especificamente o trabalho formal. É considerado trabalhador formal aquele que possui algum vínculo com a Previdência Social e apresenta registro de carteira assinada. Um maior número de trabalhadores formais (proporcional ao tamanho da população) indica a capacidade da microrregião em gerar empregos, e assim melhorar a sua infraestrutura urbana.

As variáveis X09 e X11 levam em consideração a existência de energia elétrica no domicílio e no logradouro (iluminação pública), respectivamente. A utilização de eletricidade é comumente associada a questões de potenciais de desenvolvimento, como em Hoffman (1992), que versa sobre a modernização da agricultura nas microrregiões brasileiras, e em Mata et al. (2008) sobre o desenvolvimento econômico e social dos municípios do Estado da Bahia.

Tabela 2 - Descrição das variáveis utilizadas, Microrregiões - Brasil, 2010

\begin{tabular}{|c|c|}
\hline Variável & Descrição \\
\hline X01 & Proporção da população urbana de 0 a 5 anos frequentando o ensino infantil \\
\hline $\mathbf{X 0 2}$ & Proporção da população urbana de 6 a 14 anos frequentando o ensino fundamental \\
\hline $\mathbf{X 0 3}$ & Proporção da população urbana de 15 a 17 anos frequentando o ensino médio \\
\hline X04 & $\begin{array}{l}\text { Proporção da população urbana de } 18 \text { anos ou mais frequentando o ensino } \\
\text { superior ou pós-graduação }\end{array}$ \\
\hline X05 & $\begin{array}{l}\text { Proporção de pessoas da zona urbana com } 10 \text { anos ou mais, ocupadas e que } \\
\text { contribuem para a previdência oficial (trabalho formal) }\end{array}$ \\
\hline X06 & $\begin{array}{l}\text { Proporção dos domicílios urbanos que possuem banheiro de uso exclusivo do } \\
\text { domicílio e que está ligado a rede geral de esgoto ou pluvial }\end{array}$ \\
\hline X07 & $\begin{array}{l}\text { Proporção dos domicílios urbanos que possuem abastecimento de água através da } \\
\text { rede geral }\end{array}$ \\
\hline X08 & Proporção dos domicílios urbanos cujo destino do lixo é na forma de coleta \\
\hline X09 & $\begin{array}{l}\text { Proporção dos domicílios urbanos que possuem energia elétrica oriunda da } \\
\text { companhia de distribuição e que possuem medidor }\end{array}$ \\
\hline $\mathbf{X 1 0}$ & Proporção dos domicílios urbanos cujo logradouro possui identificação \\
\hline $\mathbf{X 1 1}$ & Proporção dos domicílios urbanos que possuem iluminação pública \\
\hline $\mathbf{X 1 2}$ & Proporção dos domicílios urbanos que possuem pavimentação no logradouro \\
\hline $\mathbf{X 1 3}$ & Proporção dos domicílios urbanos que possuem calçadas \\
\hline $\mathbf{X 1 4}$ & Proporção dos domicílios urbanos que possuem meio-fio/guia \\
\hline $\mathbf{X 1 5}$ & Proporção dos domicílios urbanos onde possuem bueiro/boca de lobo \\
\hline $\mathbf{X 1 6}$ & Proporção dos domicílios urbanos onde possuem rampas para cadeirantes \\
\hline $\mathbf{X 1 7}$ & Proporção dos domicílios urbanos que existe algum tipo de arborização \\
\hline $\mathbf{X 1 8}$ & Proporção dos domicílios urbanos que não existe esgoto a céu aberto \\
\hline $\mathbf{X 1 9}$ & Proporção dos domicílios urbanos que não existe acúmulo de lixo no logradouro \\
\hline $\mathbf{X 2 0}$ & Quantidade de estabelecimentos de saúde por 1000 habitantes \\
\hline
\end{tabular}

Fonte: Elaboração própria com base no banco de dados SIDRA (IBGE) e DATASUS, 2010. 
De acordo com Sistema Nacional de Informações Sobre Saneamento (2016), o saneamento básico está relacionado com o abastecimento de água potável; o manejo de água pluvial; a coleta e tratamento de esgoto; a limpeza urbana; o manejo de resíduos sólidos; e controle de pragas e qualquer agente patogênico visando à saúde da comunidade. Assim, as variáveis X06, X07, X08, X18, e X19 estão relacionadas à infraestrutura de saneamento básico na área urbana. A utilização de variáveis correspondente a serviços urbanos, como coleta de lixo e saneamento básico pode ser encontradas nos trabalhos de Xerxenevsky e Fochezatto (2015), que analisaram o desenvolvimento socioeconômico dos municípios do litoral norte do Rio Grande do Sul.

As variáveis X10, X11, X12, X13, X14, X15 e X16 se relacionam com a infraestrutura física urbana, mais especificamente com a condição em que se encontram os logradouros, dentre outras características do entorno dos domicílios. A acessibilidade para portadores de necessidades especiais, que é um indicativo de infraestrutura, será captada pela variável X16, que indica a existência de rampas para cadeirantes. A variável X17 se relaciona com o meio ambiente indicando a existência ou não de arborização no meio urbano.

Por fim, questões relacionadas à saúde serão captadas pela variável X20, que indica o número de estabelecimentos de saúde em cada microrregião, como hospitais, policlínicas, postos de saúde, dentre outros. Sabe-se que, no Brasil nem todos os municípios possuem hospitais de referência, o que faz com que a população que necessite do serviço de saúde para casos de doenças complexas tenham que se deslocar do município de origem para outro município vizinho que forneça o serviço adequado. Os serviços de saúde, como indicador de infraestrutura e desenvolvimento, foi utilizado por Perobelli et al. (1999) objetivando identificar os potenciais de desenvolvimento dos municípios de Minas Gerais na região em torno de Juiz de Fora.

\section{RESULTADOS E DISCUSSÕES}

A análise aplicada para as 20 variáveis apresentou cinco fatores com raiz característica maior que a unidade. Após a rotação com o método Varimax, conclui-se que os fatores selecionados explicam $72,58 \%$ da variabilidade total das variáveis selecionadas. Essas informações estão apresentadas na Tabela 3. 
Tabela 3 - Autovalor (raiz característica), percentual da variância explicada por cada fator $(\%)$ e acumulada $(\%)$

\begin{tabular}{cccc}
\hline Fator & $\begin{array}{c}\text { Eigenvalue } \\
\text { (Autovalor) }\end{array}$ & $\begin{array}{c}\text { Variância Explicada } \\
\text { Pelo Fator }(\%)\end{array}$ & $\begin{array}{c}\text { Variância } \\
\text { Acumulada (\%) }\end{array}$ \\
\hline \hline F1 & 4,559 & 22,80 & 22,80 \\
F2 & 3,558 & 17,79 & 40,59 \\
F3 & 2,453 & 12,27 & 52,86 \\
F4 & 2,354 & 11,77 & 64,63 \\
F5 & 1,590 & 7,95 & 72,58 \\
\hline
\end{tabular}

Fonte: Elaboração própria com base nos resultados da pesquisa

O teste Kaiser-Meyer-Olkin (KMO) para o modelo com essas 20 variáveis apresentou um valor de $0,842^{6}$, o que indica a possibilidade de utilização desse conjunto de variáveis para operar com a técnica de análise fatorial. Em relação ao Teste de Esfericidade de Barlett, constata-se que o modelo é significativo (BTS $=7924,24)$, isto é, rejeitou-se a hipótese nula de que a matriz de correlação é uma matriz identidade, indicando que os dados utilizados são adequados ao emprego da técnica de análise fatorial.

A Tabela 4 apresenta as cargas fatoriais e as comunalidades para os fatores considerados. Os valores estão em ordem decrescente para cada fator considerado. Ademais, todos os fatores apresentaram cargas fatoriais maiores que 0,50 (destacadas em negrito), buscando evidenciar os indicadores mais fortemente associados a determinado fator. Os valores das comunalidades para todas as variáveis também se situam acima de 0,50, significando que mais da metade da variância da variável é reproduzida pelos fatores comuns.

O Fator 1 representa $22,80 \%$ da variância total das variáveis e estão positivamente correlacionadas com este fator, podendo este ser identificado como inerente as características da estrutura física (X13 - Proporção dos domicílios que existe calçadas; X14 - Proporção dos domicílios que existe meio fio/guia; X12 - Proporção dos domicílios que existe pavimentação; X10 - Proporção dos domicílios que existe identificação do logradouro; e X17 - Proporção dos domicílios que existe arborização), e saneamento básico dos domicílios (X06 - Proporção dos domicílios que possuem banheiro de uso exclusivo do domicílio e que estão ligados a rede geral de esgoto ou pluvial; e X07 - Proporção dos domicílios em que o abastecimento de água é feita pela rede geral). Assim, esse fator pode ser denominado como INDICADOR DE INFRAESTRUTURA FÍSICA E DE SANEAMENTO BÁSICO. Disto,

\footnotetext{
${ }^{6}$ Para o índice KMO: o intervalo 1 - 0,90 é ótimo; 0,89 - 0,80, muito bom; 0,79 - 0,70, bom; 0,65 - 0,60, regular; 0,59 - 0,50, ruim e menor que 0,49 , não aceitável.
} 
pode-se concluir que a infraestrutura urbana das microrregiões brasileiras possui como principal fator determinante este indicador.

Tabela 4 - Cargas Fatoriais e Comunalidade após a rotação pelo método Varimax

\begin{tabular}{c|c|ccccc}
\hline \multicolumn{1}{c}{ Variável } & \multicolumn{1}{c}{ Fator 1} & Fator 2 & Fator 3 & Fator 4 & Fator 5 & Comunalidade \\
\hline \hline X13 & $\mathbf{0 , 9 2 5}$ & 0,024 & 0,022 & 0,128 & 0,017 & 0,875 \\
X14 & $\mathbf{0 , 8 9 3}$ & 0,188 & 0,027 & 0,233 & 0,049 & 0,890 \\
X12 & $\mathbf{0 , 8 5 3}$ & 0,198 & 0,040 & 0,158 & 0,031 & 0,795 \\
X06 & $\mathbf{0 , 6 6 1}$ & 0,510 & $-0,154$ & 0,106 & $-0,237$ & 0,788 \\
X07 & $\mathbf{0 , 6 1 4}$ & 0,156 & 0,059 & 0,343 & 0,181 & 0,556 \\
X10 & $\mathbf{0 , 5 8 2}$ & 0,458 & $-0,183$ & 0,090 & 0,097 & 0,599 \\
X17 & $\mathbf{0 , 5 1 2}$ & $-0,191$ & 0,037 & 0,498 & 0,374 & 0,689 \\
\hline X05 & 0,239 & $\mathbf{0 , 8 3 3}$ & $-0,160$ & 0,069 & 0,293 & 0,868 \\
X15 & 0,168 & $\mathbf{0 , 7 3 1}$ & $-0,034$ & $-0,036$ & 0,293 & 0,653 \\
X18 & 0,133 & $\mathbf{0 , 6 7 2}$ & $-0,063$ & 0,480 & $-0,022$ & 0,704 \\
X20 & 0,129 & $\mathbf{0 , 5 8 3}$ & 0,524 & 0,160 & 0,274 & 0,732 \\
X08 & 0,414 & $\mathbf{0 , 5 1 0}$ & $-0,202$ & 0,132 & 0,214 & 0,537 \\
\hline X03 & $-0,012$ & 0,208 & $\mathbf{0 , 8 3 1}$ & 0,186 & 0,064 & 0,773 \\
X01 & 0,091 & $-0,348$ & $\mathbf{0 , 8 1 9}$ & $-0,070$ & $-0,086$ & 0,812 \\
X02 & $-0,202$ & $-0,498$ & $\mathbf{0 , 7 6 1}$ & $-0,021$ & $-0,053$ & 0,872 \\
\hline X19 & 0,096 & 0,090 & 0,186 & $\mathbf{0 , 8 2 2}$ & $-0,064$ & 0,732 \\
X11 & 0,457 & 0,058 & $-0,025$ & $\mathbf{0 , 7 3 8}$ & 0,097 & 0,768 \\
X09 & 0,429 & 0,202 & $-0,059$ & $\mathbf{0 , 5 4 8}$ & $-0,011$ & 0,529 \\
\hline X16 & 0,111 & 0,233 & $-0,129$ & 0,109 & $\mathbf{0 , 7 8 1}$ & 0,706 \\
X04 & $-0,043$ & 0,386 & 0,211 & $-0,133$ & $\mathbf{0 , 6 4 4}$ & 0,629 \\
\hline
\end{tabular}

Fonte: Resultados da pesquisa

O Fator 2 indica que $17,79 \%$ da variabilidade total dos dados originais está representada por este fator. As variáveis que compõem esse fator são: X05 - Proporção de ocupados e que contribuem para a previdência oficial (trabalho formal); X15 - Proporção dos domicílios que possuem bueiro/boca de lobo em seu entorno; X18 - Proporção dos domicílios que não existe esgoto a céu aberto; X20 - Número de estabelecimentos de saúde por 1000 habitantes; e X08 - Proporção dos domicílios que possuem coleta de lixo. Entende-se aqui que, a existência de bueiros, a ausência de esgoto a céu aberto e a coleta regular de lixo são fatores determinantes que contribuem para que a comunidade tenha melhores condições de saúde. Nessa perspectiva, o Fator 2 pode ser denominado como INDICADOR DE INFRAESTRUTURA DE SAÚDE E TRABALHO.

Em relação ao Fator 3, este está associado apenas com as variáveis relacionas a educação básica, tais como: X03 - Proporção da população de 15 a 17 anos frequentando o ensino médio; X01 - Proporção da população de 0 a 5 anos frequentando o ensino infantil; e 
X02 - Proporção da população de 6 a 14 anos frequentando o ensino fundamental. Como apresentado na Tabela 3, o Fator 3 representa 12,27\% da variância total das variáveis, e pode ser denominado como INDICADOR DE INFRAESTRUTURA DA EDUCAÇÃO BÁSICA.

O Fator 4 está associado com a proporção dos domicílios que não possuem lixo acumulado no entorno (X19); a proporção dos domicílios que possuem iluminação pública (X11) e a proporção dos domicílios que possuem energia elétrica oriunda da companhia de distribuição e que possuem medidor (X09). Sozinho, este fator representa $11,77 \%$ da variância total das variáveis e pode ser denominado como INDICADOR DE INFRAESTRUTURA DE LIMPEZA E ELETRIFICAÇÃO URBANA.

Por fim, o Fator 5 representa 7,95\% da variabilidade total das variáveis, estando relacionado com a proporção da população de 18 anos ou mais frequentando o ensino superior e pós-graduação (X04); e a proporção dos domicílios que possuem rampa de acesso para cadeirantes no entorno (X16). Pode-se então denominar este fator como sendo o INDICADOR DE INFRAESTRUTURA DA EDUCAÇÃO SUPERIOR E ACESSIBILIDADE DE PESSOAS ESPECIAIS.

Em uma escala de 0 a 100, o índice de infraestrutura urbana médio foi de 63,01 com um desvio padrão de 20,18. Isto significa que microrregiões com índice de infraestrutura urbana maior que 83,19 foram classificados com grau de infraestrutura alta (A); microrregiões com índice de infraestrutura urbana entre 63,01 e 83,18 foram classificadas com grau de infraestrutura urbana média (M); e microrregiões com índice menor que 63,01 foram classificadas com baixo (B) grau de infraestrutura urbana.

A média do indicador de infraestrutura urbana encontrada nesta pesquisa para as microrregiões brasileiras foi ligeiramente superior quando comparado com o Índice de Bem Estar Urbano (IBEU) calculado para as 15 regiões metropolitanas do Brasil, onde apresentou uma média de 60,5 (INCT, 2013).

A Tabela 5 sintetiza as informações agregadas de acordo com o grau de infraestrutura urbana. Em relação às microrregiões classificadas com alto grau de infraestrutura urbana, 82 delas foram classificadas nesse grupo, o que representa 14,7\% de todas as microrregiões. 197 microrregiões foram classificadas com média infraestrutura, representando 35,3\% do total. Por fim, $50 \%$ de todas as microrregiões foram classificadas com baixo grau de infraestrutura urbana, isto é, 279 microrregiões. Em termos gerais, no Brasil ainda prevalece uma baixa infraestrutura urbana, o que pode estar associado, em parte, ao baixo nível de 
desenvolvimento urbano do país, como observado em outros indicadores que mensuram o desenvolvimento.

Tabela 5 - Frequência das microrregiões por o grau de infraestrutura urbana (2010)

\begin{tabular}{cccc}
\hline Grau de Infraestrutura & Frequência & Percentual & Acumulado \\
\hline \hline Alto & 82 & 14,7 & 14,7 \\
Médio & 197 & 35,3 & 50 \\
Baixo & 279 & 50 & 100 \\
\hline Total & $\mathbf{5 5 8}$ & $\mathbf{1 0 0}$ & - \\
\hline
\end{tabular}

Fonte: Elaboração própria com base nos resultados

Ressalta-se que para a análise dos fatores, os escores originais são variáveis com média zero e desvio padrão igual a 1 , sendo os escores próximos a zero um indicativo de média infraestrutura urbana. Assim, quanto maior o valor do fator em relação à zero, mais infraestrutura terá a microrregião. Uma situação de relativo atraso manifesta-se através de valores negativos dos fatores. Fatores com valores maiores do que a unidade indicam que as microrregiões são intensivas naquele fator (HOFFMAN, 1992).

Nessa perspectiva, a partir da média e do desvio-padrão dos fatores para cada grau de infraestrutura urbana, podem-se fazer inferências da intensidade do desenvolvimento da infraestrutura urbana das microrregiões em relação a cada fator. Os resultados estão apresentados na Tabela 6 de acordo com o grau de infraestrutura urbana.

Dado que os escores fatoriais das microrregiões com alto índice de infraestrutura urbana, em média, foi superior a unidade $(1,2403)$, conclui-se que as microrregiões com alto grau de infraestrutura são mais intensivas no indicador de infraestrutura física e de saneamento urbano (Fator 1), seguido pelo indicador de infraestrutura de saúde e trabalho e do indicador de infraestrutura da educação básica. Entretanto, apesar do alto grau de infraestrutura urbana, essas microrregiões ainda apresentam atrasos nos indicadores de limpeza e eletrificação urbana (Fator 4) e infraestrutura de educação superior e acessibilidade à cadeirantes (Fator 5), com médias iguais a -0,0163 e -0,2280, respectivamente.

Tabela 6 - Média e desvio-padrão dos fatores de acordo com o grau de infraestrutura (2010)

\begin{tabular}{cccc}
\hline Grau de Desenvolvimento & Fator & Média & Desvio-Padrão \\
\hline \hline \multirow{2}{*}{ Alto } & F1 & 1,2403 & 0,2995 \\
& F2 & 0,7758 & 0,5246 \\
& F3 & 0,1435 & 0,6567
\end{tabular}




\begin{tabular}{cccc} 
& F4 & $-0,0163$ & 0,7041 \\
& F5 & $-0,2280$ & 0,8737 \\
\hline \multirow{3}{*}{ Médio } & F1 & 0,4431 & 0,5413 \\
& F2 & 0,0844 & 1,0794 \\
& F3 & 0,0108 & 0,9246 \\
& F4 & 0,3105 & 1,1760 \\
& F5 & 0,1789 & 1,1299 \\
\hline \multirow{3}{*}{ Baixo } & F1 & $-0,6774$ & 0,8469 \\
& F2 & $-0,2876$ & 0,9144 \\
& F3 & $-0,0498$ & 1,1254 \\
& F4 & $-0,2144$ & 0,8771 \\
& F5 & $-0,0593$ & 0,9161 \\
\hline
\end{tabular}

Fonte: Elaboração própria com base nos resultados

Ainda de acordo com a Tabela 6, as microrregiões classificadas com médio grau de infraestrutura urbana apresentaram valores dos fatores próximos a zero, em média, indicando que essas microrregiões possuem intensidade média de infraestrutura em todos os fatores analisados. Contudo, o indicador de infraestrutura da educação básica apresentou o pior resultado para essas microrregiões, enquanto que o indicador de infraestrutura física e de saneamento urbano encontra-se em melhor condição.

Para as microrregiões com baixo grau de infraestrutura, os valores negativos dos fatores indicam o atraso relativo que essas regiões têm em sua infraestrutura urbana. O pior resultado para essas microrregiões foi o indicador de infraestrutura física e de saneamento urbano (Fator 1), seguido pelo indicador de infraestrutura de saúde e trabalho, com médias para estes fatores iguais a $-0,6774$ e $-0,2876$, respectivamente.

A Tabela 7 mostra a frequência absoluta e relativa das microrregiões brasileiras de acordo com a região, o estado e o grau de infraestrutura urbana. Em linhas gerais, os resultados apontam que, a maioria das microrregiões brasileiras foram classificadas com baixo grau de infraestrutura urbana. Os resultados mostram que das 64 microrregiões da Região Norte, 61 apresentaram baixo grau de infraestrutura urbana, o que corresponde a 95,3\% das microrregiões para esta região. Nenhuma das microrregiões da região Norte apresentou alto grau de infraestrutura urbana. Além disto, todas as microrregiões dos estados de Rondônia, Acre, Pará a Amapá foram classificadas com baixo grau de infraestrutura.

Ainda para a região Norte, o estado do Pará apresentou o maior número de microrregiões com baixo grau de infraestrutura urbana seguido do estado do Amazonas, representando $36,1 \%$ e $19,6 \%$ das microrregiões para esses estados, respectivamente. As únicas três microrregiões com médio grau de infraestrutura urbana da região Norte são as 
microrregiões de Parintins, Boa Vista e Rio Formoso, localizadas nos estados do Amazonas, Roraima e Tocantins, respectivamente.

A Região Nordeste apresentou 2 microrregiões com alto grau de infraestrutura urbana, sendo elas: Caririaçu e Sertão de Inhamuns, ambas no estado do Ceará. Das 188 microrregiões da região Nordeste, 78 microrregiões foram classificadas com médio grau de infraestrutura urbana, cerca de $41,48 \%$, estando a maior parte delas no estado do Ceará $(24,3 \%)$ seguido do estado da Paraíba (16,6\%). O estado do Maranhão apresentou baixo grau de infraestrutura urbana para todas as microrregiões analisadas nesse estado. Ainda para a Região Nordeste, 108 microrregiões $(57,44 \%)$ foram classificadas com baixo grau de infraestrutura urbana, sendo a Bahia o estado com maior proporção dessas microrregiões, cerca de 20,3\%, seguida do estado do Maranhão (19,4\%).

A região Sudeste apresentou o maior percentual de microrregiões classificadas com alto grau de infraestrutura urbana, isto é, das 160 microrregiões dessa região, 76 apresentaram alto grau de infraestrutura urbana, o que corresponde a 47,5\% das microrregiões do Sudeste. De acordo com a Tabela 7, a maioria das microrregiões com alto grau de infraestrutura urbana no Sudeste está localizada nos estados de São Paulo (64,70\%) e Minas Gerais (32,89\%). Em relação ao total de microrregiões do Brasil com alto grau de infraestrutura urbana, 92,68\% se encontram na região Sudeste.

Tabela 7 - Frequência absoluta e relativa das microrregiões brasileiras segundo a região, estado e grau de infraestrutura urbana, 2010

\begin{tabular}{|c|c|c|c|c|c|c|c|}
\hline \multirow{2}{*}{ Região } & \multirow{2}{*}{ Estado } & \multicolumn{6}{|c|}{ Grau de Estrutura Urbana } \\
\hline & & Alto & $(\%)$ & Médio & $(\%)$ & Baixo & $(\%)$ \\
\hline \multirow{8}{*}{ Norte } & "Rondônia & 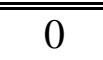 & 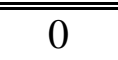 & 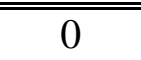 & 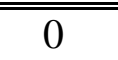 & 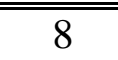 & 13 \\
\hline & Acre & 0 & 0 & 0 & 0 & 5 & 8,2 \\
\hline & Amazonas & 0 & 0 & 1 & 33,3 & 12 & 19,6 \\
\hline & Roraima & 0 & 0 & 1 & 33,3 & 3 & 4,5 \\
\hline & Pará & 0 & 0 & 0 & 0 & 22 & 36,1 \\
\hline & Amapá & 0 & 0 & 0 & 0 & 4 & 6,5 \\
\hline & Tocantins & 0 & 0 & 1 & 33,3 & 7 & 11,4 \\
\hline & Total & $\mathbf{0}$ & $\mathbf{0}$ & 3 & 100,0 & 61 & 100,0 \\
\hline \multirow{6}{*}{ Nordeste } & "Maranhão & 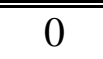 & 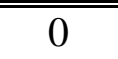 & 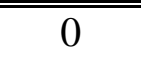 & 0 & 21 & 1019,4 \\
\hline & Piauí & 0 & 0 & 3 & 3,8 & 12 & 11,1 \\
\hline & Ceará & 2 & 100,0 & 19 & 24,3 & 12 & 11,1 \\
\hline & Rio Grande do Norte & 0 & 0 & 12 & 15,3 & 7 & 6,4 \\
\hline & Paraíba & 0 & 0 & 13 & 16,6 & 10 & 9,2 \\
\hline & Pernambuco & 0 & 0 & 4 & 5,1 & 15 & 13,8 \\
\hline
\end{tabular}




\begin{tabular}{c|c|cc|cc|cc} 
& Alagoas & 0 & 0 & 5 & 6,4 & 8 & 7,4 \\
& Sergipe & 0 & 0 & 12 & 15,3 & 1 & 0,9 \\
& Bahia & 0 & 0 & 10 & 12,8 & 22 & 20,3 \\
\cline { 2 - 8 } Sudeste & Total & $\mathbf{2}$ & $\mathbf{1 0 0 , 0}$ & $\mathbf{7 8}$ & $\mathbf{1 0 0 , 0}$ & $\mathbf{1 0 8}$ & $\mathbf{1 0 0}$ \\
\cline { 2 - 8 } & Minas Gerais & 25 & 32,8 & 24 & 42,8 & 17 & 60,7 \\
& Espírito Santo & 1 & 1,3 & 7 & 12,5 & 5 & 17,8 \\
& Rio de Janeiro & 1 & 1,3 & 14 & 25,0 & 3 & 10,7 \\
& São Paulo & 49 & 64,4 & 11 & 19,6 & 3 & 10,7 \\
\cline { 2 - 8 } Sul & Total & $\mathbf{7 6}$ & $\mathbf{1 0 0 , 0}$ & $\mathbf{5 6}$ & $\mathbf{1 0 0 , 0}$ & $\mathbf{2 8}$ & $\mathbf{1 0 0 , 0}$ \\
\hline \hline \multirow{5}{*}{ Centro-Oeste } & Paraná & 2 & 100,0 & 18 & 40,0 & 19 & 40,4 \\
& Santa Catarina & 0 & 0 & 9 & 20,0 & 11 & 23,4 \\
& Rio Grande do Sul & 0 & 0 & 18 & 40,0 & 17 & 36,1 \\
\cline { 2 - 8 } & Total & $\mathbf{2}$ & $\mathbf{1 0 0 , 0}$ & $\mathbf{4 5}$ & $\mathbf{1 0 0 , 0}$ & $\mathbf{4 7}$ & $\mathbf{1 0 0 , 0}$ \\
\hline \hline & Mato Grosso do Sul & 0 & 0 & 2 & 13,3 & 9 & 25,7 \\
& Mato Grosso & 0 & 0 & 2 & 13,3 & 20 & 57,1 \\
& Goiás & 1 & 50,0 & 11 & 73,3 & 6 & 17,1 \\
& Distrito Federal & 1 & 50 & 0 & 0 & 0 & 0 \\
\cline { 2 - 8 } & Total & $\mathbf{2}$ & $\mathbf{1 0 0 , 0}$ & $\mathbf{1 5}$ & $\mathbf{1 0 0 , 0}$ & $\mathbf{3 5}$ & $\mathbf{1 0 0 , 0}$ \\
\hline \hline
\end{tabular}

Fonte: Elaboração com base nos resultados

Esse resultado para a região Sudeste é condizente com o processo histórico da formação urbana brasileira, revelando como essas diferenças se perpetuam no tempo e não diminuem apenas com a atuação das forças de mercado. Entretanto, esse indicativo reflete a concentração das atividades econômicas e contingente populacional que possui essa região, o que faz com os investimentos em infraestrutura urbana sejam mais facilmente atraídos para esta região em detrimento de outras.

Em relação ao Índice de Infraestrutura Urbana (IIU), das 20 microrregiões mais bem classificadas com alto grau de infraestrutura urbana, 17 estão no estado de São Paulo e 3 em Minas Gerais. A primeira colocada no ranking é a microrregião de Fernandópolis (SP), seguida da microrregião de Poços de Caldas (MG). Outras microrregiões bem classificadas são as microrregiões de Marília, Limeira, Franca e Votuporanga no estado de São Paulo; e microrregiões que formam o triângulo mineiro, como Uberlândia e Uberaba. Em Hoffman (1992), foi encontrado um maior número de microrregiões mais modernizadas (em relação à agricultura) para o Estado de São Paulo. Entende-se aqui que há um transbordamento do desempenho da infraestrutura urbana para as áreas rurais nesse Estado de forma mais intensa.

As externalidades da infraestrutura urbana podem ser observadas também pelo alto valor do indicador de microrregiões que são vizinhas no Estado de São Paulo, como a 
microrregião onde se localiza a capital paulista, além das microrregiões de Campinas, Osasco, Guarulhos, Sorocaba, São José do Rio Preto e Jundiaí.

Vale destacar também a microrregião de Belo Horizonte no centro sul de Minas Gerais e a microrregião de Juiz de Fora na Região da Zona da Mata mineira, além da microrregião do Vale do Paraíba Fluminense no Estado do Rio de Janeiro.

Em relação à região Sul, metade das microrregiões apresentou baixo grau de infraestrutura urbana. Das 94 microrregiões, apenas duas microrregiões apresentaram alto grau de infraestrutura urbana, o que representa $2,12 \%$ do total para esta região. Essas duas microrregiões se encontram no estado do Paraná e são elas: a microrregião de Londrina e a de Maringá. A participação das microrregiões com média e baixa infraestrutura urbana foram, respectivamente, $47,87 \%$ e $50 \%$ para esta região.

Ainda sobre a Região Sul, esperava-se que a microrregião onde se encontra a cidade de Curitiba figurasse em uma classe de alta infraestrutura urbana. Entretanto, esse resultado nos revela o fato de que uma cidade com alta qualidade de vida e malha de transportes intraurbanos bem desenvolvidos não é capaz por si só de elevar a microrregião a qual está inserida a altos patamares de infraestrutura urbana, além de que o indicador está relativizado pelos domicílios e pela população. Entretanto, as microrregiões onde se encontra as capitais Curitiba, Florianópolis e Porto Alegre obtiveram valores de 76,7, 75,2 e 70,5 do indicador, o que é considerado moderado em termos de infraestrutura urbana.

A Região Centro-Oeste também apresentou apenas duas microrregiões com alto grau de infraestrutura urbana, representando $3,84 \%$ das microrregiões para esta região. As microrregiões mais bem classificadas para o Centro-Oeste são: Catalão, no estado de Goiás, e Brasília no Distrito Federal. Ainda para a região Centro-Oeste, as microrregiões com médio grau de infraestrutura representam $28,84 \%$ do total desta região; e com baixo grau de estrutura, tem-se, para esta região, 67,3\% das microrregiões, inclusive a microrregião do entorno de Brasília.

A Figura 1 apresenta as microrregiões do Brasil em forma de mapa de acordo com o grau de infraestrutura urbana. 
Figura 1 - Mapa das microrregiões segundo o grau de infraestrutura urbana (2010)

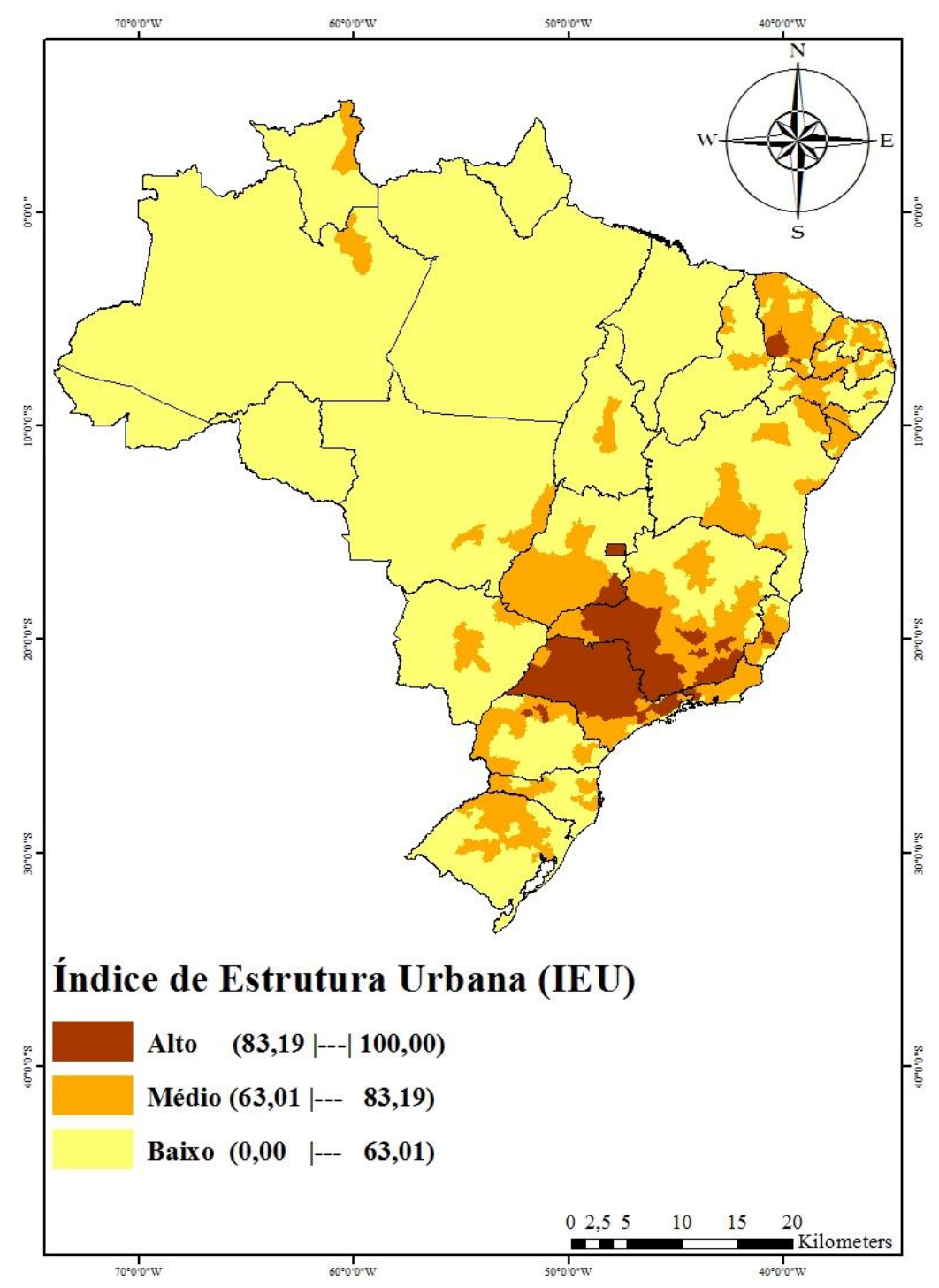

Fonte: Elaboração própria

\section{CONSIDERAÇÕES FINAIS}

Através da análise relativa dos fatores determinantes do nível de infraestrutura urbana das microrregiões brasileiras procurou-se identificar os aspectos que mais contribuem para essa infraestrutura. A aplicação da análise fatorial permitiu a extração de cinco fatores: F1: Indicador de Infraestrutura Física e de Saneamento Básico Urbano; F2: Indicador de Infraestrutura de Saúde e Trabalho; F3: Indicador de Infraestrutura da Educação Básica; F4: 
Indicador de Infraestrutura de Limpeza e Eletrificação Urbana; e F5: Indicador de Infraestrutura da Educação Superior e Acessibilidade à Pessoas Especiais.

O Índice de Infraestrutura Urbana (IIU) nos permitiu classificar as microrregiões em Alto, Médio e Baixo grau de infraestrutura urbana. Na prática, a construção de um índice que permita fazer um ranking e que mostre a situação das microrregiões brasileiras tem por objetivo instrumentar as instâncias de governos locais ou regionais, como por exemplo, as secretarias de desenvolvimento econômico e social e as secretarias de infraestrutura estaduais descentralizadas, podendo assim localizar o potencial e os principais fatores e conflitos das microrregiões pela análise de cada um dos subindicadores do índice aqui elaborado, para depois formular estratégias de desenvolvimento que se ajuste a sua realidade e permitam potencializar o desenvolvimento da infraestrutura urbana nesse meio.

Os resultados apontaram que 50\% das microrregiões apresentaram baixo grau de infraestrutura urbana, e apenas $14,7 \%$ apresentaram alto grau dessa infraestrutura. O restante das microrregiões foi classificado com médio grau de infraestrutura (35,3\%). Das microrregiões brasileiras com alto grau de infraestrutura urbana, 92,68\% estão situadas na região Sudeste, mais especificamente nos estados de São Paulo e Minas Gerais.

A Região Norte não apresentou microrregiões com alto grau de infraestrutura urbana, além de conter apenas três microrregiões com grau médio de infraestrutura, o que faz com que essa região necessite de políticas públicas voltadas para o desenvolvimento microrregional e que objetive amenizar o atraso relativo em comparação a outras regiões do Brasil. As regiões Nordeste, Sul e Centro-Oeste apresentaram cada uma apenas duas microrregiões com alto grau de infraestrutura urbana.

A distinta distribuição de microrregiões dotadas de infraestrutura urbana entre as regiões do país pode, em parte, ser explicada não somente pelo processo de formação das cidades brasileiras, mas também pelo atraso na adoção da dinâmica gerencial dos governos descentralizados em relação à identificação, formulação, execução, acompanhamento e avaliação de resultados de políticas voltadas ao desenvolvimento da infraestrutura urbana.

Não obstante, é importante salientar os efeitos oriundos das externalidades positivas que uma gestão municipal voltada a excelência da oferta de serviços públicos, em termos de infraestrutura urbana, gera para as cidades vizinhas e assim para toda a microrregião. Esses efeitos, que a priori são resultados de ações de longo prazo, são capazes de chamar a atenção dos governos localizados em uma esfera superior como uma região que detêm as atividades 
econômicas e uma dinâmica social avançada, podendo captar investimentos com maior facilidade para o desenvolvimento de toda a microrregião.

Por fim, sugere-se em pesquisas futuras que as medidas de bem estar urbano sejam continuamente atualizadas por meio da incorporação de novas variáveis, métodos e base de dados que melhor possam representar o desenvolvimento dessa infraestrutura urbana, além da investigativa da relação entre convergência de renda e urbanização. A sinergia entre a atualização dos indicadores e as ações coordenadas dos governos descentralizados será de suma importância na identificação das regiões mais deficitárias quando do planejamento de políticas voltadas ao desenvolvimento regional.

\section{REFERÊNCIAS}

ABIKO, A. K. Introdução a Gestão Habitacional. Texto Técnico TT/PCC/12. Escola Politécnica da Universidade de São Paulo (USP). Departamento de Engenharia da Construção Civil. 35p. São Paulo, 1995.

AUDRETSCH, D. B.; FELDMAN, M. P. R\&D spillovers and the geography of innovation and production. American Economic Review, v. 86, n. 3, p. 630-640, 1996.

BANCO INTERAMERICANO DE DESENVOLVIMENTO (BID). Um Nuevo Impulso a la Integracion de La infraestructura regional em America Del Sur. BID, dic. 2000. Disponível em: http://idbdocs.iadb.org/wsdocs/getdocument.aspx?docnum=35317367

BLAKLEY, E. J.; BRADSHAW, T. K. Planning local economic development: theory and practice. Califórnia: Sage Publications, 2002.

BRASIL. Ministério do Planejamento e Orçamento. Sistema Nacional de Indicadores Urbanos. Projeto PNUD BRA 92/028: SEPURB, 1996.

CHOGUILL, C. Ten steps to sustainable infrastructure. Habitat International, v. 20, n. 3, 1996.

CLEMENTE, A. HIGACHI, H. Y. Economia e desenvolvimento regional. São Paulo: Atlas, 260p, 2000.

ESTACHE, A.; FAY, M. Current debates on infrastructure policy. World Bank, Nov. (Policy Research Working Paper, n. 4410), 2007.

FERREIRA, V. C. P. Administração Pública Gerencial. In: Administração Pública Contemporânea: Política, Democracia e Gestão. Organizadores: Marcos Tanure Sanabio, Gilmar José dos Santos, Marcos Vinicius David. 246p. Juiz de Fora: Ed. UFJF, 2013.

FERREIRA JÚNIOR, S.; BAPTISTA, A. J. M. S.; LIMA, J. E. A modernização nas microrregiões do Estado de Minas Gerais. RER, Rio de Janeiro, vol. 42, nº 01, p. 73-89, jan/mar 2004.

FIORI, S.; ORTH, D. M.; ROSSETO, A. M.; FIORI, S. Indicadores Urbanos: Monitorando o Ambiente Construído. In: Anais do IV Encontro Nacional da Anppas. Brasília (DF), 2008. FJP \& IPEA - FUNDAÇÃO JOÃO PINHEIRO \& INSTITUTO DE PESQUISA ECONÔMICA E APLICADA. Desenvolvimento Humano e Condições de Vida: Indicadores para a Região Metropolitana de Belo Horizonte, 1980-1991. Belo Horizonte, 92 p., 1998. 
GIANPIERO, T. Public infrastructure: definition, classication and measurement issues. 24 Jan. 2009 (MPRA Paper, n. 12990). Disponível em: <http://www.mpra.ub.unimuenchen.de/12990/>.

HADDAD, P.R. et al. Economia regional. Fortaleza, BNB, 1989.

HOFFMAN, R. A dinâmica da modernização da agricultura em 157 microrregiões homogêneas do Brasil. Revista de Economia e Sociologia Rural. Brasília, v.30, n.4, p.271290, out-dez, 1992.

INSTITUTO DE PESQUISA E PLANEJAMENTO URBANO DE CURITIBA - IPPUC. Qualidade de vida em Curitiba. 158 p. 1996.

INSTITUTO DE PESQUISA ECONÔMICA APLICADA (IPEA). Atlas da vulnerabilidade social nos municípios brasileiros/editores: Marco Aurélio Costa, Bárbara Oliveira Marguti. - Brasília : IPEA, 2015. 77 p. ISBN: 978-85-7811-255-4.

INSTITUTO DE PESQUISA ECONÔMICA APLICADA (IPEA). Infraestrutura social e urbana no Brasil: subsídios para uma agenda de pesquisa e formulação de políticas públicas. v. 2 (912 p.) Brasília : Ipea, 2010.

INSTITUTO NACIONAL DE CIÊNCIA E TECNOLOGIA (INTC) - OBSERVATÓRIO DAS METRÓPOLIS. IBEU: índice de bem-estar urbano. Org.: Luiz Cesar de Queiroz Ribeiro, Marcelo Gomes Ribeiro. 1. ed. Rio de Janeiro: Letra Capital, 2013.

INSTITUTO PÓLIS (IP). Núcleo de Gestão Municipal do Instituto Pólis. Medindo a Qualidade de Vida. Autor: José Carlos Vaz. DS $\mathrm{N}^{\circ}$ 27. Disponível em: <http://www.polis.org.br/uploads/312/312.pdf> Novembro, 1994.

JOHNSON, R. A.; WICHERN, D. W. Applied multivariate statistical analysis. Prentice Hall, 1992.

LEMOS, J.J.S. Indicadores de Degradação no Nordeste Sub-úmido e Semi-árido. Revista SOBER, 2000, p.1-10.

MATA, H.; PONCIANO, N.; SOUZA, P. e MIRA, E. Padrão e determinantes do desenvolvimento econômico e social dos municípios do Estado da Bahia: a dicotomia rural - urbano. Anais: XLVI Congresso da SOBER. Rio Branco, 2008.

MELO, C.; e PARRÉ, J. Índice de desenvolvimento rural dos municípios paranaenses: determinantes e hierarquização. Revista de Economia e Sociologia Rural, vol. 45, nº 02, p. 329-365, abr/jun 2007.

MELO, C. Índice relativo de desenvolvimento econômico e social dos municípios do região sudoeste paranaense. Revista Análise Econômica, Porto Alegre, ano 25, n 47, p.149-164, setembro de 2007.

MINGOTI, S. Analise de dados através de métodos de estatística multivariada: Uma Abordagem Aplicada. Editora UFMG, 2007.

NAHAS, Maria Inês Pedrosa. Indicadores intra-urbanos como instrumentos de gestão da qualidade de vida urbana em grandes cidades: discussão teórico-metodológica. Belo Horizonte: Instituto de Desenvolvimento Humano Sustentável, 2003. Disponível em: <http://www.virtual.pucminas.br/idhs/site/imagens/nahas1.pdf $>$. Acesso em: fevereiro/2017.

NAHAS, M. I. P.; GONÇALVES, E.; SOUSA, R. G. V.; VIEIRA, C. M. Sistemas de Indicadores Municipais no Brasil: experiências metodológicas. In: XV Encontro Nacional de Estudos Populacionais (ABEP), Caxambu, Minas Gerais. 2006.

NAHAS, M.I.P.; RIBEIRO, C.A.; STEVES, O.A.; MOSCOVITCH, S.K. \& MARTINS, V.L.A.B. O Mapa da Exclusão Social de Belo Horizonte: metodologia de construção de um instrumento de gestão urbana. Cad. ciênc. soc., V. 7, N. 10, p.75-88, 2000. 
NETO, A. e PEROBELLI, F. Potencial de desenvolvimento cultural das microrregiões de Minas Gerais: uma análise espacial. Seminário de Economia Mineira, CEDEPLAR, 2010. OLIVEIRA, G. B. de, LIMA, J. E. de S. Elementos endógenos do desenvolvimento regional: considerações sobre o papel da sociedade local no processo de desenvolvimento sustentável. Revista FAE, v.6, n.2, p.29-37, 2003.

ORGANIZAÇÃO PARA COOPERAÇÃO E DESENVOLVIMENTO ECONÔMICO (OCDE). Urban Infrastructure: finance and management. OECD, 1991. v. 1.

PEROBELLI, F.; OLIVEIRA, A.; NOVY, L. e FERREIRA, M. Planejamento Regional e Potenciais de desenvolvimento dos municípios de Minas Gerais na região em torno de Juiz de Fora: Uma aplicação de análise fatorial. Revista Nova Economia. V 9. N.1, julho, 1999.

PROGRAMA DAS NAÇÕES UNIDAS PARA O DESENVOLVIMENTO (PNUD). Atlas do Desenvolvimento Humano no Brasil 2013. Disponível em <www.atlasbrasil.org.br/2013/>. Acesso em 17 de agosto de 2017.

PNUD; IPEA \& FJP - PROGRAMA DAS NAÇÕES UNIDAS PARA O DESENVOLVIMENTO; INSTITUTO DE PESQUISA ECONÔMICA APLICADA \& FUNDAÇÃO JOÃO PINHEIRO. Atlas do Desenvolvimento Humano no Brasil. 2000. <http://www.undp.org.br/default1.asp?par=24>. Acesso em 02/08/2017.

RESENDE, M.; FERNANDES, L. e SILVA, A. Utilização da Análise Fatorial para Determinar o Potencial de Crescimento Econômico em uma Região do Sudeste do Brasil. Revista Economia e Desenvolvimento, $n^{\circ}$ 19, 2007.

SEPÚLVEDA, S. Elementos conceituais do desenvolvimento sustentável microrregional. In: Desenvolvimento sustentável microrregional: métodos para planejamento local. Tradução de Dalton Guimarães. 296 p. Brasília, 2005.

SISTEMA NACIONAL DE INFORMAÇÕES SOBRE SANEAMENTO (SNIS). Disponível em <http://www.snis.gov.br/>. Acesso em 17/08/2016

SOARES, A.; GOSSON, A.; MADEIRA, M. e TEIXEIRA, V. Índice de Desenvolvimento Municipal: hierarquização dos municípios do Ceará no ano de 1997. IPARDES - Revista Paranaense de Desenvolvimento, n.97, p. 71-89, set./dez. 1999.

SOUZA, P.; PONCIANO, N.; BRITTO, M.; MATA, H. e GOLINSKI, J. Padrão de desenvolvimento tecnológico dos municípios das regiões Norte e Noroeste do Estado do Rio de Janeiro. Anais: XLV Congresso da SOBER. Londrina, 2007.

SMILOR, R. W.; WAKELIN, M. Smart infrastructure and economic development: the role of technology and global networks. In: KOSMETSKY, G.; SMILOR, R. W. (Ed.). The technopolis phenomenon. Austin: University of Texas, 1990.

STIMSON, R. J.; STOUGH, R, R.: ROBERTS, B. H. Regional Economic Development: Analysis and Planning Strategy. 2nd Ed. Springer. New York, 2006.

TAVARES, H. M. "Estratégias de desenvolvimento regional. Da grande indústria ao Arranjo Produtivo Local?". Revista Brasileira e Gestão e Desenvolvimento Regional, v. 7, pp. 51 a 68, 2010.

TURRA, S.; BAÇO, F. M. B. Identificação do nível de desenvolvimento regional das microrregiões paranaenses por meio da análise fatorial. Revista de Economia, v. 40, n. 1 (ano 38), p. 97-114, jan./abr. 2014.

UDERNAN, S. "Políticas de Desenvolvimento Regional no Brasil: Limites de uma nova agenda para Nordeste". Associação Brasileira de Estudos Regionais e Urbanos, 2008.

XERXENEVSKY L. L; FOCHEZATTO, A. Índice relativo de desenvolvimento socioecônomico dos municípios do litoral norte do Rio Grande do Sul: uma aplicação da análise fatorial. Boletim Geográfico do Rio Grande Do Sul. Porto Alegre (RS). Ed. 25, p. 31-55, 2015. 
ZMITROWICZ, W.; NETO, G. DE ANGELIS. Infraestrutura Urbana. Texto Técnico TT/PCC/17. Escola Politécnica da Universidade de São Paulo (USP). Departamento de Engenharia da Construção Civil. 40 p., 1997.

Recebido em 31 de outubro de 2017. Aceito em 27 de novembro de 2017. 